Article
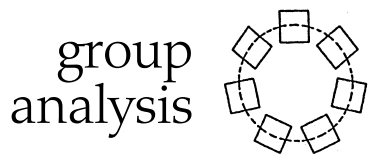

\title{
Unthinking the Closed Personality: Norbert Elias, Group Analysis and Unconscious Processes in a Research Group: Part II
}

\author{
Hans-Peter Waldhoff
}

In Part I of this article (Waldhoff, 2007) the author revealed Elias in the triangle between psychoanalysis, group analysis and research, discussing previously unpublished documents. Part II will record and discuss the development and dynamics of the first Congress Group ('C-Group') of the Group-Analytic Society, again with reference to previously unpublished verbatim records, and which highlight especially the relationship between Foulkes and Elias.

Key words: Elias, Foulkes, Congress Group, research group, group tensions

It was Bion who pointed out the danger to which groups or the functioning of groups were exposed, in differing degrees, by the shift into the modus of 'basic assumption groups', guided mainly by primary processes.

The 'Congress Group' (C-Group) does not engage in 'conversation without an object', as Elias described pure analytic groups. The development of free group association is correspondingly limited. But a group which speaks with scientific intent about group dynamics evidently does not remain untouched by those dynamics. 
The first recorded meeting of the Congress Group was documented in Part One of this article (Waldhoff, 2007).

\section{Second Recorded Meeting, 24 October 1948}

Participants - Dr Anthony, Dr Dalberg, Dr Elias, Dr James, Dr de Maré, Dr Taylor and Dr Yates. The group leader, Foulkes, is absent, but, at his request, the group first deals with a question in a World Health Congress questionnaire.

As before, Elias opens the main part of the meeting with a statement which refers to the written record of the previous meeting.

Elias . . . I wondered whether you thought it was too loose for our purpose - not concentrated enough . . . I think it was, as a first meeting, very good. It gave me a lot of material . . more than you were aware of . . .

He goes on to say that the group's aim is to publish something and continues to

Elias . . suggest that there are two ways of doing this: (1) We can each try to write something in which we are individually . . interested . . . There is another way (2) which I should like us to take. That is that we gain, by means of our discussion as a group, some clarification of our own problems ... then one of us can ... write up a particular part, for example, the beginning of a group ... I have . . . made an attempt to write down my own conclusions from last month's meeting ... It records what I gained and what were my conclusions . . . and says what I think one could begin to publish [for] an article for a symposium on 'Problems of the First Meeting.' . . . I have done part. I hope someone will do the next part . . . If we could do that with regard to certain central problems of group analysis it would be ideal. . .'

Before reading his report, Elias says:

. . . things I have written down are . . . things which you all know . . . I suggest that, as I read, [you] write down what you think is wrong with it whether anything is formulated in too definite a manner. I have tried . . . to put something, particularly, of Dr Foulkes's spirit into it, who always insists on ... flexibility ... while, as you know my own tendency is that things should be clear-cut.

Elias reads his report - which deals with group tensions at the first meeting and how to keep them at the appropriate level 
(where they should be). He then asks the group: 'What is wrong? Where are the mistakes?' These questions are answered, proceeding to the second part, i.e. 'What the level of tensions during the first meeting is' (my italics).

The paper read by Elias is not included in the transcript. Regarding the writing process, he advocates an attempt at a group approach.

He tells the others that they are not aware how much material they had given him. This could be understood as dividing up the conscious and the unconscious between himself and them. On the other hand he repeatedly enquires about mistakes he might have made, apologizes for writing down things which they all probably take for granted and even conjures up the flexible spirit of the absent group leader, Foulkes.

Thus Foulkes stands here in Elias' view for the pole of flexibility, informality and fluidity and perhaps, in Elias' later terminology, for involvement, whereas Elias stands for discipline and detachment. But Elias attempts to take on Foulkes' part as well.

As group leader Foulkes can be seen as a father figure, who arouses feelings of rivalry in Elias, but who, paradoxically, represents in his behaviour more the motherly, group-analytic, flowing pole as opposed to the disciplined fatherly pole, which Elias laboriously attempts to stress in a spirit of cooperative conflict, a troublesome balance of involvement and detachment, thereby practising his later theory of science.

Elias now encounters increasing resistance of various participants on several points, among them his comparison of individual and group analysis. He says: '. . I I wonder whether what I wrote is entirely wrong . . I think, theoretically speaking, the whole situation is made on the average to give more relief if one is alone ...'

To his most insistent critic, he says - 'My difficulty is this ... How can one generalise?' (turning to de Maré) 'That is behind your question? The problem which is the stumbling block? How can one make so sweeping a statement and generalise? ... How can one talk about problems of the first meeting generally? Do you think one can?'

James answers: 'I do not think it is terribly valuable to. As you said, first meetings differ so much. They are not really a group at the first meeting'. 
Elias' skilful reduction of the variety of resistance to a common denominator, namely resistance to his attempt at generalization, is to a certain degree appropriate. Thus he also shows how one can generalize in a meaningful way.

But is the resistance directed only or only primarily against generalization in general or against a particular kind of generalization? Or more against the 'generalizer'? Or even against the General pushing the group forward, a General who might be perceived as having usurped the leadership?

Is the resistance only at the level of the working group? Can the form of 'scientization' proposed protect the group from the dynamics of the unconscious? Or does it (or id) return again, as long as it is not translated into spoken communication and self-reference?

Before a short break, James, Yates and Elias again take up the theme of tensions in the first meeting of therapeutic groups (and, as it seems, with latent, but no manifest, self-reference):

James: You can go half-way to meet them and get a personal relation with each of them, or you can really try to help them to understand the tension.

Yates: Therefore you have got to state . . . that there is tension.

Elias: To state that you have here a situation where you have to cope with tensions ... One has to ask oneself, what is the appropriate level of tension which they can bear? I must not go too much below and I cannot go too much above . . I think that is one of the central problems of the first meeting.

Elias did not succeed in integrating this conception of an appropriate level of tension into a general theory on therapeutic groups, mainly because Foulkes contradicted him later. But he saves it up for decades, until placing it at the heart of his own sociological small-group theory illustrated by the example of football figurations and in the form of the concept of 'groups in controlled tension' (Elias and Dunning, 1982: 111). In the development of his theory of the small group Elias explicitly names the theoretical foundations of group therapy and Foulkes in a footnote - but as having been 'put aside' (1982: 122, footnote 1$)$.

As 'the main motor of group dynamics' he sees a 'complex of reciprocally dependent polarities' (1982: $118 \mathrm{ff}$.) - precisely as it is elaborated here as a driving force of Elias' theory formation, an example of the way in which the personal dynamics of a 
scientist can sharpen perception of the analogous dynamics of the object of his research.

Whereas in the previous course of the discussion group experience from the standpoint of the therapist was the main point of reference, in the following sequence another point of reference is added: the comparison and the tense competition with the theory and practice of Bion, the most important group-analyst beside Foulkes.

Bion did not trouble himself to consider whether, how or to what degree the tension in the first or any other meeting can be reduced. His refusal to meet any of the expectations participants might have from a group leader, and instead simply to observe and describe what happens seems to have caused irritation not only in his groups, but also in the C-Group.

Elias: After hearing your discussion last time and thinking it over, I came to the conclusion that what Bion does is wrong as a consistent pattern. There may be a reason occasionally to do it. I had almost the feeling that to make it a theory . . . it must be done in such a way - that seemed to me wrong.

Yates: Bion's technique is quite, quite different. The content in his group treatment doesn't matter much. It doesn't matter what they talk about . . . I think all of us agree that the content matters ...

Taylor: . . . I had the same feeling: this attitude of Bion's is almost a neurotic symptom. He wants to disappoint and frustrate the group. He doesn't only do it with the group. I heard him last Thursday. He disappoints everybody . . . He wants to disappoint everybody.

Yates: It is quite deliberate . . .

Elias: My impression is that he cannot help it.

de Maré: I agree.

Elias: To have the elasticity to choose, sometimes Bion's technique is very good.

To have no other technique is wrong . . . (my italics).

The thread running through the discussions on the surface is the attempt, undertaken above all by Elias, to arrive at scientifically-'generalizable' statements about therapeutic groups - and a counter-tendency which repeatedly threatens to break this thread whenever participants cast doubts upon the various specific generalizations, while Elias gains the impression that these doubts refer to generalizations in general.

James reacts to an attempted summarization by Elias:

James: Every group differs. You can never tell.

Anthony: How can you generalise that every group differs from every other group? 
Elias: That is very true. You can only judge in what respect one group differs from another if you can compare...

And elsewhere -

Elias: The reason why I brought in individual analysis is this: one can see the specific characteristics of the first meeting of group therapy only if one compares it with something which isn't group therapy. (my italics) . . . I am stating the obvious in that the situation is different, only to find out what effect that has on the people involved in the situation.

One could ask whether it is really necessary to say these things in this circle. Is this a flight from the more difficult aspects the job of this group has, as in one of the classical basic assumptions identified by Bion? A task drift? (Hinshelwood, R.D., 1987, 116-18, 136-48). Are we still in a working group here, or are we at least from time to time in what Bion called a basicassumption group?

In spite of all these difficulties Elias keeps the planned article in sight. He is not without support.

James (to Elias): What you have written is rather different from the way we are speaking - more in line with what I would think is right. You begin rather generally. I think it is a useful kind of approach . . .

Improvements on details are suggested. Yates refers to a passage in which Elias says of the group leader that '. . . he had to vary his approach according to the constitution of the group ... and according to his own personality'. Elias agrees. Here, in the circle of group leaders, a more conscious self-reference enters into the debate. Yates again brings up Bion in the discussion and Elias answers: 'It would be quite wrong on our part to develop a rigid theory. One cannot impose it'. Whereas Bion is identified here with rigidity, the opposite pole is 'Foulkes's flexibility' (Anthony) (my italics).

Again and again the group returns to the anxieties and tensions in first group meetings. 'Fear of the unknown' is mentioned (Taylor), which Elias approves, himself adding 'implicit rivalry' - for which the C-Group could have provided a lot of material if it had actually studied its own communication (my italics).

It is typical of this group that its own communication as a possible level of research remains largely implicit, but nonetheless 
is both expressed and disguised in this latent form. Thus strong tensions are not only discussed generally but can also be heard unarticulated as such in the C-Group, e.g. in the remarks of Yates ('silly') and de Maré (to Elias): 'You are not convinced. I would like to know what other people think' (my italics).

The tension is relieved by laughter at two points which characteristically indicate self-reference.

Elias: Is there such a thing as 'beginner's anxieties'?

James: In the therapist - which we have not discussed yet! (laughter)

And, towards the end of the meeting -

Elias: Is there anything else that the conductor must not convey at the first meeting - apart from not being omnipotent?'

Anthony: I suppose that includes omniscience too! (laughter)

Why does 'omniscient' in an answer to Elias make everybody laugh? This is an implicit but certainly not entirely unconscious allusion in the group to its own discussions and the special role of Elias.

The group then seems to open the door to Elias' project for an article. Yates proposes that each of them should write down what he or she says in the first group meeting.

Elias: We could do some good . . in this article. One . . thinks about one's own technique. If we could make the reader sit up and think, then we would do something very good.

Anthony: Sounds a little rigid - but we could.

They agree to prepare something for the next meeting.

\section{Third Meeting, 6 November 1948}

Participants - Elias, Foulkes, James, de Maré and Taylor. Nothing is said about the agreement reached at the previous meeting. Elias opens instead with the proposal that they should first discuss what Foulkes wishes to discuss. Foulkes responds to Elias' attempts to adopt a comparative approach by saying: 'You compare six horses with two dogs ...' Elias retorts, 'You compare two methods of psychotherapy ...' (my italics).

Quite apart from the tension in the air, the group found it difficult to reach an agreement on clear comparisons. Should individual or dyadic psychotherapy be compared with group 
therapy or psychoanalysis with group analysis? Should the first hour of a group therapy or of specific group analysis be compared with a first hour of individual analysis on the couch or with the preceding diagnostic interview? Would it be better to compare the first hours instead of only the first hour?

This is the typical difficulty of a minimally structured group discussion with just a few basic guidelines, and the Congress Group now discusses this characteristic field of tension between formalized-disciplined and informalized-open styles but without the resource of self-reference, or evaluating its own experience.

Foulkes: I can handle a group nearer - give them more definite instructions. Or I can handle it leaving it open what is allowed and what is not allowed - let the group find its own level, other things being equal. I prefer this. It is more difficult but more interesting. You bring out more things . . . What would be comparable, say, to a group member getting up and putting on his coat, or lighting a cigarette? The group member has no reason from the beginning to know whether this is acceptable behaviour or not. In analysis a patient will say Can I smoke?' and you have to say, as a rule, 'No, better not'.

Elias: You might say - 'Why do you want to smoke?'

Foulkes: In a group I would say 'Certainly' . . . If you say 'No, better not smoke' they may be perfectly all right. If you leave it to the group, the fact whether they smoke or not tells you a lot. A freer field, a less rigid frame of reference but you get more information.

It is worth making an anticipatory digression to a different group here, because training groups, although they are not themselves directly therapeutic groups, are 'allowed' to come closer to the therapeutic pole, as these are a preparation for the leadership of therapeutic groups. They consequently offer more room for manoeuvre in the open regressive domain than the C-Group could - or thought it could - allow itself as a research group. In this case of a training group led by Foulkes and with Elias as a member we have the detailed notes of Foulkes.

One of the things when I had to take a more personal role was when Elias raised the question of smoking, and I gave a very free account of my feelings about it, and there was a lengthy discussion, which again tended to become rather technical. . . .

Foulkes emphasizes '. . . the importance of rather talking what they feel instead of living it out'.

At the seventh meeting of the T-Group Foulkes describes an episode in which he first attempts in a friendly manner to point 
out to de Mare that he had betrayed a considerable degree of animosity towards the group leader and that this bore all the characteristics of a fundamental transference problem.

He continues:

The point about it all is that this matter was taken up by almost the whole group as if I had rebuffed de Maré severely ... Dr Elias seemed to get more and more hostile, too. He suddenly asked 'May I smoke?' having matches and a cigarette in his hands. 'Of course you may - are you asking me?' I said, 'but you know what we were saying about it.' 'May he smoke, please?', insisted Dr Doniger, on my left, even more provoking the impression that it was entirely my taboo, and that I was a terrible tyrant, that I had to be implored not to treat his poor flock too badly.

After that '... Elias, with enormous tension and almost like acting aggression, but I think he controlled it even (my italics), lit his cigarette. This was the climax of hostility expressed . . .

There is no smoke without fire. Tension and aggression and their control are key themes for Elias, in the C-Group and in his entire work. Transfer, acting out, projections, the unconscious and the preconscious are expressed mutely, which is not untypical for a traumatized person. If they are not symbolized they cannot be treated at all, or at best only implicitly, in sociological civilization theory.

We return to the earlier discussion in the C-Group which now revolves around comparative aspects of individual and group analysis.

Elias: What effect has this difference on the patients in the first meeting? Generally, according to our present day knowledge that a definite situation produces certain attitudes no matter what the individuals are that are in that situation ... individuals make variations but it is the situation itself which produces certain attitudes . . . it would be interesting to know what does this situation produce - the individual analytic situation - different from the group-analytic situation?'

Foulkes: Psycho-analytic situation 'produces', or is in danger to produce, putting it all in inverted commas. The whole situation is taken as distinct from life.

Elias: What effect has this?

Foulkes: Encourages regression and allows for regression . . .

Elias: . . . The chance to feel oneself in a child situation . . . seems to be greater in the individual situation than in the group situation . . .

Foulkes: I wouldn't say that. Initially, as far as one can generalise, that sort of thing would tend to make it less at ease. 
Foulkes later goes more deeply into his last-mentioned point of comparison.

Foulkes: I think the deep unconscious fear is more played on by the analytic situation than by the group situation.

Elias: I have asked round as much as I could and most people . . . have agreed with me that in the beginning an analysis promises, or tends to give, immediate relief. That is what I relied on when I made this statement. My inner formulations were: 'While, in later stages, individual analysis creates, I should almost say, pain of a depth which group analysis can never reach, at the beginning it is more likely to give greater relief.

Foulkes can agree with this if it refers to the first four weeks, but not in regard to the first meeting. Elias does not take him up on his reference to unconscious fear. Afterwards the discussion gets hung up and goes around in circles. It again turns on problems of generalization. Elias says that he does not understand and Foulkes that he is only trying to help. The records end with the word 'confused'. In between Elias polemizes against the conception of the self-regulatory group and raises the question of the group leader, all referring to other groups or to groups in general. Once again, it can be read very differently, when it refers to the group engaged in the discussion.

Elias: . . . it can easily work out that one, so to say, in one's mind transforms the group into some mysterious being which develops by itself - in a mysterious way. I remember that word 'self-regulating'. I don't deny that, to some extent, the group is self-regulating, but I would insist . . . that the conductor is the conductor. Without the spontaneity of the group he can do nothing. At the same time he does actively observe whether this integration goes on and he helps as far as he can.

Foulkes: That is a different question.

Elias: This idea that really one can leave it all to the group . . .

Foulkes: I am certainly not of that opinion. I don't think the conductor can leave it for a moment to the group, in a sense - but you can define his role more precisely or less precisely. . .

Elias: I do not understand . . . There is . . . some activity in the group, some element of self-regulation in it. But the conductor must want to know in his own mind that he wants this group of people - who are at first moment strangers to each other - that he wants this feeling of strangeness to wear off and he wants them to develop some feeling of being a unit, and of sharing something. This doesn't mean that they are friends. Only on the basis of this group feeling can these hostilities come into the open . . . The problem was - there are these initial difficulties coming from the strangeness of being among strangers 
and yet being asked to confide in a doctor. The conductor is there to help to do that ...

Taylor: I agree.

Foulkes: It isn't to define but sometimes he may do a wrong thing by helping to wear it off.

So Elias, who thinks a certain level of tension is useful, wants to help against tense feelings of strangeness, Foulkes, who tries to work consistently against tension, seems to be reluctant to help with the reduction of this specific tension, which both migrants must know all too well.

Taylor: I asked the group to compare symptoms as a task. I helped them to establish a bond - something which they shared. Then I have the first unifying situation in the group. The rest I leave to them but part help them . . .

This is the first contribution, after a good three quarters of the meeting have passed, to what had been or apparently had been agreed on for this session at the previous meeting. The group then turns to the question of how Bion actually holds his meetings together.

Elias: It may be by the enormous common tension which he creates. He may also create a common hostility towards himself which may also integrate.

Foulkes: I believe that group therapy, even group analysis, rests more on supporting features ... This supporting element comes in the group not so much deliberately from the conductor . . . I want to avoid this idea that group analysis in principle is less ready to deal with basic problems than analysis.

Elias: I am a bit unhappy about the outlook. Again and again it comes to a point where it seems that one can almost say everything about everything - and I know that cannot be true . . .

James: I felt that too. The form in which you present the paper and in which we criticize is fallacious. We certainly did not criticize but the discussion went on as a criticism ... .

Foulkes: We have agreed very definitely on certain statements.

Elias: I feel at the moment a little bit confused rather than enlightened.

Confusion can be a key word for the rest of the discussion. Two statements on content stand out.

Foulkes: Looking back on a first session: (1) everybody participated and was interested; (2) has the group understood what they are here for? Have they understood, ideally, what is expected of them and what they come here for? (3) Have they understood, ideally, that they can exchange remarks, 
that they are a group, that they are not remaining each an individual connected with me? (4) Are they quite happy? Supposing there was a big tension, are they happier? (5) Can they be serious, and also can they laugh?'

Criteria for a good start to a group then. But how far are they valid for the Congress Group?

There are two more asides:

Elias: How can you expect them to have understood what they are coming for? ... .

de Maré: That frustrating element of the group is terribly important. That prolonged frustration for an individual in a group is very important.

Elias makes a concluding remark in which he brings the question of self-reference or self-reflexivity of the group back into the group by discussing the discussion of the beginning of other therapeutic groups as an experience of the C-Group itself. He also expresses his frustration at being at the end of the session where he had hoped they would be at the beginning.

Again and again the group process seems to spring back to its beginnings. One is aware of a seemingly almost regressive undertow working against the intended development.

Must the group tarry forever in an eternal first meeting in order to win insights into the generalizable aspects of a group of this kind?

Elias: This brings us to the problem which I hoped we would discuss today. One of the experiences of the group itself was by comparing the different ways in which each member of the group starts a group. I think each has realized more fully . . . how many different ways of starting a group there are. If we could convey something of this in an article . . . By getting to know of other methods one can . . . loosen a little bit the structure of one's own tendencies in starting a group. We would say what possibilities of starting a group there are - starting, say, at the Bion pole and going through various shades to the opposite of Bion . . .

Foulkes: I don't know whether Bion knows himself what his method is.

\section{The records end in indirect speech:}

Taylor says that Bion reported a therapeutic group in Human Relations and described what he did in a group but never said anything of his relation to the group. He gives no lead to the group and leaves them confused. (Compare Bion, 1961: 29 where he says himself that he does not know what his method is). 


\section{Fourth Meeting, 21 November 1948}

Participants - Anthony, Elias, Foulkes, Darborg, James, de Maré, Taylor and Yates.

Elias opens the session with the themes also central to his sociological works - discipline and time. 'We must discipline ourselves to do certain work as a group.' Various possibilities are discussed. James would like to know the feelings of the others in regard to what had been achieved so far and what improvements each could propose. De Maré finds this pointless, as long as all of them have not received a copy of the report.

Elias: These reports must be considered as confidential. Nothing should be shown to outsiders as our considered opinions.

Presumably the records of the group meetings are meant here. It now turns out that evidently only Elias and Foulkes had access to them. This casts a new light on some of the opposition, for example on the part of de Maré. Tacit power differentials in groups in general are subsequently thematized - that almost all participants in the C-Group set great store by wearing the doctor's white coat as group leaders; that they sit on special group leaders' chairs.

It is also now made explicit who will be in charge of the work on the article.

Elias: Perhaps Foulkes and I will sort out something from these discussions and make a draft . . . but in addition it would be a very good thing if we could write something individually. Is that something very difficult do you think?' Yates: Yes.

Elias and Foulkes offer all who wish to make a written contribution individual support. Elias emphasizes that each must find a topic which suits him.

James: I think we have tried lots of different alternatives and not found a direction. If we actually discussed something which has been written . . .

Elias: That is what I have done...

James: We have not had the typescript to make written comments on it.

Taylor demands more factual material.

Elias: What seemed to me lacking was a clear framework into which to order this material - and a method of ordering it. If there would be a group . . . people 
who had blue colour vision . . . They could not possibly know they had blue colour vision. You can only know it if you come together with people who have different colours . . . That is why I think we had to compare group psychoanalytic treatment with individual psychoanalytic treatment . . Just to describe a few things that we do - that is not enough.

James: It would not be just a few things.

Elias: All things are not enough. It is not a question of adding one thing to another...

James: Let's use our experience here.

In 'all things are not enough' Elias' plea for synthesis is all too evident. If one wishes to be scientific, one must reach a higher level of summary comparison.

Latently, however, the other members seem to hear the overtones of an omnipotent, overtaxing (scientific) super-ego aiming at 'omniscience', against which those invited to supply material rebel, suspecting a degrading division of labour between the suppliers of raw materials and the refiners of the product.

James' demand 'to use our experience here' means in the manifest context, as his subsequent elucidation reveals, quite simply what should be taken for granted, namely that everyone should bring in his experience from outside. To shift the emphasis, it would make much better sense to read the situation as: Why don't we use the group experience we are making here and now for theory formation? But this reading remains latent.

Elias: There is one general way of procedure which I would recommend . . . not so much to say 'I do this and this' and 'I do that and that' but to look upon it . . . from outside and to say: 'One of the possibilities to conduct a first meeting is this ...' You might say that they are innumerable. But you will find that they lie on a scale between two extremes ... ( turning to Taylor): You give very definite instructions. That is one extreme ... On the other hand. we have the attitude of the conductor who is frustrating from the first moment - who says very little . . . as it seems Bion does sometimes. Here we have a framework - two variables: the kind of group one has and the personality of the Conductor.

(Incidentally, 'Conductor' is written with a capital ' $\mathrm{C}$ ' here, and his importance is thus emphasized. This leads us to question who transcribed the records. It seems likely that it was Foulkes' secretary at the time, later his wife, Elizabeth Foulkes.)

This methodical proposal to regard experiences in which one is strongly involved as if from outside was published by Elias (Elias, 
1956), then further differentiated until the final version was presented as the conception of involvement-detachment-balances.

In what follows several participants seem better prepared in regard to the contents of the discussion, or they react more communicatively to Elias' endeavours. The group brings further knowledge about group work to light. Key information often surfaces wherever the transfer of knowledge, especially of implicit knowledge, is related to the group process. But this almost always remains, in Hegelian terms, 'in itself' and not also 'for itself' and is hardly ever consciously perceived by the group as self-reference.

Elias: You would tell them individually something beforehand about the group? What would you say?

Foulkes: You cannot generalise . . .

Elias: Don't you say certain things which you usually say - more or less repeat? Foulkes: Each occasion is too singular.

Elias: You are sitting before the group for the first time.

Foulkes: Better to assume I don't know much about them. I would start from the end. I want, ideally, a certain move to take place.'

Elias: What would you do?

Foulkes: . . . A little time would pass . . . I would find out to what situation I am talking.

Elias: You . . . have to say something.

James: Why does he have to say something?

Foulkes: At this stage the group can expect one to say something.

Elias: On most occasions you would say something. What would you say?

Foulkes: Can I turn that and say - what would I want to convey?

Elias: No. One possibility - not standardized.

In the following fifth session Elias draws the conclusion: 'By conveying you must inevitably make a more immediate appeal to the emotional side of the patients'. This casts a new light on this debate. We can now describe it in the additional light of the later developments in Elias' sociology of knowledge and science as concerning more the gradual shift towards the balance of involvement and detachment and less the alternative between 'saying' or 'conveying'.

But Foulkes's last question does not seem to come to the heart of the matter. Descriptions of a different kind come up:

Dalberg: Each may express his or her own opinion on what is said so that we see it like a crystal . . . an image of synthesis respecting difference. 
Anthony: . . I usually seize upon a key word and wait for that and from that the group starts growing.

Foulkes: What is it that one wants to convey: that it is understood why one is there? ... I welcome exchange. I stop myself ... I make it understood either by words or by conveying that it is welcome; that they can say anything they like at any time ... I support the understanding of free exchange undisciplined, as it were. (my italics)

Could it be said that the question about the use of disciplined words, disciplined scientific language, is answered with searching, free-floating, 'undisciplined' positions?

Participation in the research group described here fluctuates, although on this day nobody contradicts Yates' statement about therapeutic groups: 'regular attendance is essential' (my italics). One of the group leaders, Elias, had suddenly disappeared from the group in the preliminary phase of the CGroup. The other, Foulkes, will do the same, and not for the first time. Is it possible to describe this aspect of the group with Bion as a special form of the basic assumption group, a group which, in its considerable dynamics, is thrown back upon the unconscious basic assumption that what is at issue is fight or flight instead of research? Are we perhaps confronted, with forms of knowledge and with the 'scientific establishments' (Elias, 1982) which convey them, in which what matters is predominantly the struggle with the object of research? Or is it rather the fear and flight from it? Is it a matter of methodical rigidity inadequately designed to contain fear? Are scientific object-relations denied here, especially in situations in which one could unexpectedly discover oneself in the mirror of the research object?

It is precisely in this sequence that James reports on a patient diagnosed as paranoid, that is to say on an 'expert' in feelings of flight and fight.

James: He has been raising this issue: why have I got a special chair, why do I wear a white coat and why do I come in last?

Anthony: You have got a white coat?

Taylor: That is one of the things. To wear a white coat - that is very important.

It transpires that all except Anthony have a special chair and a white coat; and that even paranoia can have its productive aspects, for example in bringing power relations into the debate. 
Then, after a long silence:

Elias: What about the silence? (with reference to groups in general.)

James: I would minimize the silence by looking round in a friendly way . . .

Anthony: . . . It has been my good fortune always to have a 'speaker' . . .

Taylor: There is never a group without a 'speaker' . . .

Yates: When he drops out then it is dreadful. Then they really have to begin to do some work.

The interesting thread running through the concluding phase of the discussion - the time remains strictly limited to two hours - can be depicted by a series of scattered quotes:

Elias: . . what personality structure in the Conductor would be more inclined to this or that type of technique? . . Everyone has a favourite approach . . .

James: The kind of method I am interested in now is exactly the opposite from what my personality structure would have let me to do five years ago. I have learnt from Foulkes - the exact opposite of my personality. I should have thought you would all have expected me to give a lecture. (The records note: 'general amusement'.)

Elias concedes that personality structure and training play a part (my italics).

Elias: One of the uses of such an article would be to convey to other people the experiences which some of you have had here - to say how many possibilities there are...

James: The thing we have in common is to try to pass the responsibility to the group ...

Anthony: The easier you make it for the patient the longer the integrating process. I make it easy. Therefore it takes longer . . .

James: . . . The sooner they face this tension the better . . .

Elias: How soon one puts the burden of the tension on them - that is the main point . . .

James: It is the speed with which I don't take the burden off the group. (my italics)

\section{Fifth Meeting, 4 December 1948}

Participants Anthony, Dalberg, Elias, James, de Maré, Taylor and Yates. Foulkes is absent.

Elias begins by informing them that he has attempted 'to get something ready for writing', but needs the advice of the group. They discuss whether a Dr Grimwood, who is writing a work on group therapy, should be allowed to participate as a 
guest at the next session. They agree to accept his participation for one meeting.

Elias would like to bring the discussion about the beginning of a group to an end soon.

Elias: The End of the beginning: what we had in mind was not so much to have your particular beginning but to have samples of how one can possibly begin ...

Trying to write about it, I wanted to find out what are the differences, what types there are. Perhaps one problem is (which we have not yet discussed at all) not why you do it in that particular way but what is the specific effect of one way of doing it in contra-distinction to the other way of doing it . . .

Elias then characterizes his first idea about the main difference in the therapeutic technique as not being quite right and reformulates it, thus -

Elias: At the one end of the scale is the conductor who gives very systematic advice, who clearly states . . . what the patients' attitude should be . . A At the other end, represented here by James, no explicit instructions but, at best, implicit hints by means of behaviour . . . Is not the primary difference that some of you think it right to approach the ego, the intellect, of the patients - perhaps because intellectual approach limits fears (my italics) and, as the more usual approach, makes the transition from outside into the group easier? ... On the other hand, the approach (non intellectual or non verbal) stimulates far more the emotions . . . can be interpreted by the patients far more in different ways . . . One appeals to the ego; the other is more likely to involve emotional aspects too (my italics). What would be the possible effect of this difference? ... The other difference, far easier to approach, is the one which Anthony expressed by using this word 'gradualism'. James' approach . . . by its lack of definiteness, seems to me anything but gradual. Anthony's approach has the . . . aim of keeping the tension in the first meeting relatively low and of leading very gradually to the desirable tension. . . . what possible effect can that have? ... Do you think these methods can be as independent of the personality that each of you would, for experiment's sake, be willing or able, next time you start a group, to try something following the opposite model? . . .

Taylor: . . . The group Conductor is part of a group in an emotional field. He can either help this field to some sort of solution or he may not . . .

Taylor: . . Everybody has been a member of different groups. This is a therapeutic group - which they have never experienced before in their lives. They have to be told what the difference is . . .

Elias: Have they got to know? . . .

James: . . . the group should find out for itself that this group is different from other kinds of group they have been to. I have learned this from Foulkes. If they find it out for themselves it is a more real experience . . . 
Elias: (1) We all seem to agree that the tension should not become too great in the first meeting. (2) Let the weight of the activity shift on to the group itself . . .

\section{A later sequence:}

Yates: Fundamentally we are doctors. I think it is a principle in modern medicine not to do anything without getting your patient's co-operation and explaining what is happening...

James: It is just in the name of that principle that I would say nothing . . . I think it is characteristic that you say 'we' or 'doctors'. I think one should speak for oneself . . .

Elias: When I listen to your reasons I have an odd feeling. Most of the reasons are not taken from this . . group situation . . . There are extraneous reasons: because the doctor always does it . . . The central point is: accept the possibility that there are different ways of doing it - but what is the actual effect on the patient?

Anthony: How far do people realise ... that talking is therapy? They have weekly interviews and are still waiting for treatment

So, the group now talks about tension and ambivalence. And here, once again, the question of self-reference arises. Reference is made to the manner of talking in the group, to the more anonymous medical We-group identification in comparison to the group-analytic rule of self-reference of individual speakers in group discussions. Elias seems irritated by the introduction of a professional 'we' identity, from which he is also excluded, as 'extraneous', as '... not taken from this particular group situation'.

'We want as much tension as the group can stand' says James at this point.

Soon afterwards the ambivalent tension level seems to transform the group again into a basic-assumption group, and yet again when it is dealing with the issue of generalisation.

Elias: You try to convince me that it is too early to make any generalisations whatsoever but I am not convinced.

Taylor: You are right perhaps but we don't know.

Elias: Quite.

At this point of high tension, Elias suddenly begins to speak about a member of de Maré's group, a stutterer.

Elias: It was a lively group. Overwhelmed him with questions for half an hour.

$\mathrm{He}$ answered in fairly good humour. Afterwards one can feel that he is 
furious. I feel it has done him lots of good. I may be wrong. Anyhow, what type is that who can stand, at the first meeting, such an onslaught? Is it individual or can one say anything generally?

Can we hear an unconscious identification with someone in whose case it is conceivable that the high level of internal tension breaks up the continuity in the flow of his speech?

Elias makes an appeal which we could easily see in relation to his own situation:

Elias: Why not make it easier for the Conductor in the first group? Let him profit by your experiences . . . We must . . try some generalisations.

Then, a short sequence on tension:

Elias: Tension is . . the lever by means of which the therapist works ... Anthony stressed the consistency of the attitude of the Conductor throughout the treatment. Is it possible, during the first meeting, that he can deviate too much from the attitude he is going to take later on?

Anthony: Do you mean consistency or rigidity?

Elias: I mean what I say.

Content and group process, the discussion on tension and the development of tension in the group, which is speaking, interlock here. But the rest of this session seems disjointed. Fragments catch the eye:

Dalberg: . . .the prima donna is dangerous for the others . . .

Elias (not refering to the prima donna): Direct approach arouses resistance sometimes. Indirect approach gives the idea I do it alone - myself (see Elias, 2005: 261)

James: The only cure is personal anxiety. You cannot teach that in a book . .

Elias: Everyone is reluctant to increase his tension. If the Conductor is not attentive is there any tendency to decrease tension? Should he not watch that they do not get too easy?

James: Anxieties of the therapist could be a whole chapter if we could speak honestly.

Anthony (to Elias): You don't feel we are progressing gradually?

Elias: Yes. I do.

Elias: . . . or we start with the entrance of a new member. If we feel we need to discuss integration we can do so. This is the programme for the next meeting.

James: Dr Grimson will be here next time.

Anthony: $\mathrm{He}$ is the new member whom we integrate.

Here, Anthony employs a now familiar psychoanalytic and group-analytic technique. What is special is that this group, 
with its self-definition as a research group, obviously regards itself as something special, completely untouched by the group dynamic tensions of therapeutic groups; it is remarkable that it so seldom relates the contents of its discussions on group processes to its own group process.

Then Anthony suddenly speaks about children's groups: James offers to write something over Christmas about the anxieties of the therapist.

de Maré: This question of meeting outside the group - sub-groups. I have had so many catastrophes.

James: My idea is to circulate something for everyone to read . . .

Taylor: de Maré's problem is acting-out . . . If they act it out it becomes a foreign body within the group. . .

The topics of 'anxieties' and 'children's groups' in the discussions could point to a renewed regression of the C-Group. It is seen as potentially leading to catastrophes if something is acted out, that is if something which happens in the group is not spoken about inside it. Is this also happening in the C-Group perhaps because its 'intellectualized' understanding of itself as a research group keeps it at a distance from its own non-thinking processes?

Between the penultimate and the final session of the C-Group, Foulkes intervenes one more time in letter form. As a 'Postscript to the Symposium Meeting (...) on Dec. 4th' he writes on 8 December 1948:

I do not agree ... that it is the conductor's job to keep the tension at a maximum level and make the group bear as much as they can . . . I do not even think it is the conductor's job to keep to an optimum degree of tension. I should have thought that, as far as the conductor is concerned, he is out to diminish tensions and anxieties consistently (my italics) in the first group as well as in all the others. Diminishing tensions is part of the therapeutic process itself. New tensions arise consistently from new material being brought up and from new facets of personalities being activated and coming to a clash ... One must also carefully separate a tension inside the individual, in between individuals and the tensions affecting the whole of the group. It doesn't seem that this group quite follows Dr Elias's intentions, namely to bring out objective relationships between different actions, attitudes, reactions etc., on the part of the conductor or on the part of the group, and the consequences of these relationships ... ${ }^{1}$ 
So, after the group leader had stayed away from the meeting, he informs the group by letter of their results, registers the fact that the group is not following the intentions of the scientific co-leader he had engaged, and even contradicts Elias quite bluntly.

\section{Sixth Meeting, 11 December 1948}

Participants: Anthony, Dalberg, Elias, James, de Maré and Taylor.

James reads a letter from Dr Grimson, the intended guest, who cannot come. The records note: 'Elias thinks a little time should be devoted to Foulkes' postscript' and then quotes him verbatim:

Elias: May I point out to fix for our protocol and for Foulkes what is the general standard of agreement among us, and Foulkes too, about tensions . . . (my italics)

Elias: Foulkes has brought it home to us that the whole problem of tension needs further elucidation . . . the whole discussion is still almost at the personality level . . . what you say at the moment is 'that is how I almost instinctively handle the thing . . . It is . . natural that everyone has his preferred attitude ... this is not the scientific level. That would be that, out of this natural, uncritical tendency to have this and this attitude, we would know much more about what I said before: 'if I keep the tension high then this happens; if low, then that happens. We have not yet advanced to that stage . .' (my italics)

Elias formulates more and more clearly what he sees as the task of the group. It will seldom be possible to gain such a deep insight, no matter how fragmentarily, into a real, unprotected and unvarnished research process, a look behind the scenes of the kind Elias loved to take in his own research: re-discovering the once obvious. A new type of implicit knowledge about analytical experiences of group dynamics is to be raised to an explicit scientific level and brought into a scientific stage of development. But is Elias' question about 'when-then relations' and 'objective' relationships suitable as a technique of synthesis for the free and undisciplined exchange of ideas? Would one not be more likely to find this type of relationship in formalized and disciplined groups? Does this type of synthesis fit for seemingly chaotic process structures? But from his point of view at the time the search for such regularities still seemed essential. 
James: You have to stage-manage to see it is a successful communication. Elias: I always feel how much is still just groping in the dark . . . If one could analyse instinct (quite a wrong word) it really means accumulated experience ...

de Maré: I think there is a difference here which we have not got down to, which depends upon a definition of tension . . . you can go to a film where there is terrific tension but you find it bearable . . . in an unsatisfactory group there is great tension and it isn't endurable...

Elias: Let us start with the concrete problem: What happens if new people enter the group? ... I remember the scene last time ... I saw myself asking anxiously for regularities and you were pitying me - one cannot generalise ...

Elias tries to ask detached questions about general regularities in the highly involved group process. An attempt to achieve ironic and self-ironic distance is also unmistakable. Elias summarized this structure much later in a radio talk.

... Edgar Allen Poe . . . wrote ... A Descent into the Maelstrom . . . he describes this dreadful natural phenomenon . . . a huge whirlpool opens up ... which swallows up everything ... Poe ... depicts how a boat with three fishermen, brothers, gets caught up in the undertow of the funnel of the whirlpool. One ... falls overboard and drowns, the other two are swept along the high wall of the funnel, which narrows towards the bottom, with a lot of flotsam and jetsam. And the older brother sits there full of fear and completely paralysed . . . The second brother . . . begins to look around in the funnel . . . he discovers certain regularities in the flotsam and jetsam: round objects move down more slowly to the bottom of the funnel than square objects and smaller objects more slowly than larger objects. And this, if you like, is the way in which a researcher forms a theory, in which an overall view, a synthesis, almost regularities, can be recognized. (Elias, 2005: 171)

\section{He continues:}

And now he puts what he has found out into practice and encourages his brother. He . . . takes one of the barrels which were intended for the fish, ties himself to the barrel and tries to persuade his brother to do the same. But his brother is . . . full of panic. So . . . he jumps overboard. He had detached himself a little from the situation; he could see it without being overcome by his feelings. Tied to the barrel he jumps into the water and then sees how the boat slowly moves faster and faster into the depths, while he sinks much more slowly and finally, when the funnel closes again, comes back to the surface. 
This is an example of the relationship between detachment and involvement. The one is overcome by the situation, by the dangers of the situation. The other asks what the actual structure of the situation is. And because he recognizes this structure he can save himself, although this of course is not always the case. (Elias, 2005: 171)

In more pacified social associations and groups the balance of danger shifts in the direction of psychic rescue; it is more a question of psychic survival.

This is also the case with this research group when it encounters the seemingly chaotic undertow of collective primary processes. The shrewd description of his situation in the group suddenly occurs to Elias. He stops himself just as he is about to speak about the entry of new members, and advances this analysis of the group process, of this group's process. This could be translated to mean that since he had joined the $\mathrm{C}$ Group, he felt himself drawn into the maelstrom by the undertow of the Bionian basic assumption group which was so alien to his concept and even more to general concepts of research groups.

In this group, and maybe in his person, anxiety repeatedly comes to the fore. In a notable splitting-off process, the group refuses to grant Elias, or itself in the person of Elias, or only grants on occasional moments, the recognition of regularities necessary for psychic survival in the group, for its physical survival as a group, and its survival in an outcome, the planned article. From his point of view the group throws him back again and again into the whirlpool. There he searches for the regularities, which will rescue him or all of them.

But as in a game of cat and mouse he is almost always caught just before a synthesis materializes. This is what he experiences as the snare of the pre-scientific approach. And this is the reason for the desperate intensity of his endeavours to rescue himself onto the level of scientific synthesis above the whirlpool of emotions.

The question arises of the relationship between anxiety and method. (Devereuse, G., 1967)

Elias: I am . . convinced that there must be regularities, only we have not yet found the right method of getting hold of them.... What regularities there are one can only find out gradually . . . If we could pool our experience, look out for regularities, we could find them . . . It is an aim of every scientific group. ... I am sure that at a future time one will . . . be able to distinguish . . . certain types of groups ... 
Here the group structure of the development or the hindrance, of knowledge becomes visible. But as part of this collective process, Elias often takes over the role of a lonely fighter, a scientific homo clausus.

But unconscious processes are 'a city visible but unseen' (Rushdie, S., 1988). Consequently group analysis can be understood as a process of rediscovering the obvious.

Elias takes up again the theme of new members. Dalberg compares the role of the group leader with that of parents preparing children for the arrival of a new sibling. James finds that the newly-arrived person is generally a foreign body, but at first does not trigger off any real tension.

Dalberg: He must say something to be one of the group but if he monopolises the first meeting he will be almost expelled.

Elias: How do they do it?

Taylor: If we knew. (Laughter)

Elias mentions that he had attended many groups as a visitor and had felt very little animosity. Groups do not react to visitors as strongly as to members, Dalberg says to Elias - who is a group member and not a visitor.

In the context of aggression Elias mentions a member of de Marés group, who took over the role of leader.

Elias: Those who are well integrated appear to have been members for longer. Taylor: Suppose A, B, and C were the core. D is introduced and fits in very well. It will be said that $\mathrm{D}$ has been there from the very beginning and that $\mathrm{B}$, who has always been an outsider, came later.

Anthony refers to children's groups in which such structures can be recognized with particular clarity.

Anthony: I have had two boys capable of taking over the group leadership. Very difficult because the group had split up ...

The repeated recourse to the example of children and the fear of splitting up may be an indication of regression in the group discussion, but the potential of regression would at the same time also have become visible, as before. If the rivalry between two reputed therapists or scientists remains unspoken, the recourse 
to young boys fighting openly can be a half-step along the road to verbalization.

Elias also takes an interest in the phenomenon of 'unconscious understanding' (provisionally called 'telepathy') as a subsidiary problem. He refers here for the first time to the unconscious.

Elias: These things happen in every-day life. Group treatment gives us more concrete observations.

In a discussion as to whether, in the case of dominant group members, what matters is social status or personality, Elias remarks, 'Social mask and personality are not different. They fuse into one unit'.

The theme of homosexuality comes up and Elias comments: 'I am not sure how often homosexuality is openly discussed'.

This is the last surviving record of the Congress Group. Towards the end, Elias asks the members to bring as much concrete material as possible with them to the next meeting on the topic of what he calls 'the status battle of the newcomer with the others'. He therefore does not assume that this is the last session. But this request follows directly upon the following statement:

Dalberg: How to dissolve a group is just as important as how to start one.

At the very end James says -

James: When the group gets disturbed they begin to wonder whether it is really worth coming . . .

de Maré: Seems to bring them to reconsider the whole thing. The usual complaint is that they don't want to go over the same story again. I don't know why they say that because they never do.

In spite of all the 'repetition compulsion' the C-Group did not do so either.

Elias asks what the group as a whole means for the patient, then they talk about the dissolution of groups and Elias speaks of the status battle of the 'newcomers' with the others.

Taylor: That really belongs to the integration.

Elias: But you only get at it from the angle of the newcomer. 
And so Elias has the final word in stressing that what counts is the perspective of the outsider as a sociological condition for knowledge which supplements the psychological condition of detachment (Elias, 1982).

In the case of his long working process about involvement and detachment Elias later gave up the over-emphasis on detachment in favour of the conception of a balance between involvement and detachment. Opening the way to this form of controlled de-controlling of emotional controls allows also for the controlled opening of the homo clausus, the closed personality, in the direction of the homini aperti, the open, interdependent personalities. It is a 'flexibilization' of figurations in and in between people.

In the group-analytic movement Elias gradually slid into the position of a personal outsider, who, at first thanks to Foulkes, remained an important source of theoretical reference, later becoming an honorary member of the Group-Analytic Society.

Elias maintained his presence as a basic theoretician in group analysis (Dalal, 2004) but it remained for him an individualized experience seen predominantly from the perspective of an observer. Shortly before his death he emphasizes the fruitfulness of his group-analytic experience for his scientific seminars and lectures; he had been sensitized for the reactions of his audience and for the psychological significance of short silences (DLA Marbach).

Foulkes attached so much significance to the Congress Group that he later included the text presented by it to the 1948 World Health Congress in one of his books. This text applies groupanalytic experience to science and especially to sociological research as a group process.

Intellectually all are agreed that in sociological studies the observer forms an integral part of the situation or field, but persons vary greatly in their sensitivity to the application of this principle in their own case. This factor in itself is a significant bar to good communication. (Foulkes, 1964: 278)

Thus Elias position as an observer is integrated. It is, above all, of interest that Foulkes entitled the text 'Study of Communication in a Group by a Group' - a programmatic title, which shows, as result of a learning process, 'what we should do'; namely, courageously study our own communication in groups as the 
best empirical material we possess. We can read this as a programmatic appeal to move the highly influential aspect of selfreference in groups from the unconscious to the conscious level, from the wild and projective mise en scène to a more civilized setting in words, to symbolization.

In this light, the application of self-reference and self-reflexivity precisely to research groups appears to be a matter of course, although it is still branded as exotic in the practice of theory formation in 'normal science', as it is standardized by the scientific establishments.

\section{Note}

1. Unless otherwise indicated, all verbatim quotations are taken from the group records of the Congress Group and the accompanying correspondence in Elias' Literary Estate (see DLA Marbach, A: Elias 983).

\section{Acknowledgement}

This article is dedicated to my encounter group in the Seminar for Group Analysis Zürich (SGAZ) led by Hymie Wyse and to my family, Michaela, Kevin, Laura-Isabell and Clara Marie, in encounters with whom I also discover many things about myself. I also owe thanks to Michael Schröter, Karl Oeter and Sally Willis, and especially to my wife Michaela ArtmannWaldhoff, with whom I spent some time in London preparing this article and who was of great assistance in research at the Wellcome Foundation.

\section{References}

Bion, W.R. (1961) Experiences in Groups and Other Papers. London: Tavistock. Dalal, F. (2004) 'Macht, Scham und Zugehörigkeit: Eine radikale gruppenanalytische Theorie', in M. Hayne and D. Kunzke (eds) Moderne Gruppenanalyse. Gießen: Psychosozial Verlag.

Devereuse, G. (1967) From Anxiety to Method in the Behavioural Sciences. The Hague and Paris: Moulton and Co.

DLA Marbach, A: Elias 1535 (Elias' Literary Estate). Letter to Dennis Brown, Amsterdam, 29 November 1989.

Elias, N. (1956) 'Problems of Involvement and Detachment', British Journal of Sociology 8(3). 
Elias, N. (1982) 'Scientific Establishments', in N. Elias, H. Martins and R. Whiteley (eds) Scientific Establishments and Hierarchies, pp. 1-35. Dordrecht, Boston, and London: Reidel.

Elias, N. (2005) 'Autobiographisches und Interviews', Gesammelte Schriften Vol. 17. Frankfurt-am-Main: Suhrkamp.

Elias, N. and Dunning, E., (1982) 'Zur Dynamik von Sportgruppen', in Sport im Zivilisationsproze\&gothicdoublssl/cápp. 105-22. Münster: Lit Verlag.

Hinshelwood, R.D. (1987) What Happens in Groups. London: Free Association Books.

Rushdie, S. (1988) The Satanic Verses. London: Viking.

Waldhoff, H-P. (2007) 'Unthinking the Closed Personality: Norbert Elias, Group Analysis and Unconscious Process in a Research Group: Part I', Group Analysis 40(3): 323-43.

Wellcome Library, Archives and Manuscripts, $P P / S H F / C .6 / 5 / 7$ and $P P / S H F /$ B.10

Hans-Peter Waldhoff teaches sociology and social psychology at the University of Hanover and has a group-analytic training at the Seminary for Group Analysis, Zürich. Address: Prof. Dr. Hans-Peter Waldhoff, Lange Str. 14, D-31582 Nienburg/Weser, Germany.Email: waldhoff@ish.uni-hannover.de 